\title{
NOTES ON THE MARRIAGE FLIGHTS OF SOME SONORAN ANTS.
}

\author{
By William Morton Wheeler.
}

Myrmecological literature contains many accounts of the marriage-flight of ants, but in nearly all cases the descriptions are fragmentary, owing to the complexity of the phenomena, the great area over which they occur and the obstacles, such as forests, hills or buildings which in most localities interfere more or less with observation. Moreover, the actual mating of the males and females often takes place high in the air or even at night, so that one is apprised of the occurrence of a flight only by finding the recently fecundated and deälated queens running about on the ground. The following observations made during the past summer near Cloudcroft, N. M., and later while I was accompanying the Cornell Biological Expedition across the deserts of southern Arizona, are in some respects as incomplete as others which have been published, but since they illustrate interesting peculiarities in the behavior of a few of the more conspicuous ants of the Sonoran region, it seems advisable to record them.

\section{Liometopum apiculatum Mayr.}

This ant, which has huge females and males, out of all proportion to the small workers, is peculiar to the live-oak zone, or "encinal" of the dry mountains of Texas, New Mexico, Arizona and Colorado and therefore does not live at altitudes above 6,000-7,000 feet. At the latter altitude near Wooten, in the Sacramento Mountains of New Mexico, I found it to be very scarce. Undoubtedly it is abundant at lower elevations in the same range. During the marriage flight, however, the males and females are carried by aircurrents to considerably greater altitudes. July 3, while walking down Haine's Canyon, a few miles from Cloudcroft, I saw numerous males of apiculatum, which had fallen on the road at altitudes between 8,000 and 8,500 feet. As some of them were still alive the marriage flight of the species must have occurred on this or the preceding day. They were being rapidly dragged away as food by foraging Formica fusca workers. July 5, near Russia, at an altitude of 9,400 feet, I detected four deälated apiculatum queens, each in a small cavity under a stone. All of them were dead and 
more or less decomposed, showing that they had been wafted to this altitude the previous summer and had perished, probably from cold, while endeavoring to found colonies. These observations strengthen Forel's and my contention that in mountainous regions queen ants are often borne up by air-currents to elevations at which the physical conditions will not permit them to establish the species. It is very probable that this process continues year after year and that it may constitute an appreciable drain on certain ant-populations at lower altitudes.

\section{Pogonomyrmex barbatus $\mathrm{F}$. Sm. subsp. rugosus Emery.}

July 29 we visited the ancient ruins of Casa Grande, nine miles south of Florence, Ariz. In the rooms on the ground-floor of the three-storied portion of the structure still standing we found vast numbers of males and females of Pogonomyrmex barbatus rugosus, only a small portion of which were still living. The marriage flight of these large ants must have occurred a day or two previously, and the swarms, for some reason, had entered the low, narrow doorways of the ruin and accumulated on the floor in such masses that several bushels could have been collected.

3. Pogonomyrmex barbatus F. Smith subsp. molefaciens Buckley.

At Tempe, Ariz., the marriage flight of this ant took place at 5 p. m., July 31, nearly a month later than the flights I observed many years ago in Central Texas. Thousands of males and females issued from the large, flat nests in the irrigated fields about the town and soon disappeared in the cloudless sky. On the following day, August 1, the fecundated females were seen in great numbers digging their craters in the soil. They preferred the damp margins of the puddles left by recent rains and the banks of the irrigating ditches. So numerous were the little craters that their peripheries were often in contact. The females were busily bringing up the moist earth in their psammophores as pellets one-eighth of an inch in diameter and depositing them near the orifice of the eccentric burrow.

\section{Pogonomyrmex (Ephebomyrmex) imberbiculus Wheeler.}

Near Deming, N. M., I witnessed the marriage flight of this ant at 10 a. m., July 12. The black males were flying rapidly to 
and fro about the branches of a few small lote bushes (Zizyphus lycioides) in the open desert, in precisely the same manner as I have seen the males of Prenolepis imparis dancing about the Japanese barberry bushes in April in the Arnold Arboretum, near Boston. The winged females of imberbiculus were far from numerous and were found running on the ground near the lote bushes. Mating was not observed.

\section{Atta (Moellerius) versicolor Pergande.}

The marriage flight of this fungus-growing ant is very different from that of any ant I have observed, and was witnessed under unusually favorable conditions. We had left our camp July 30 about 30 miles north of Florence, Ariz., and were crossing the desert on our way to Phoenix. The air was very still and clear after a heavy rain on the preceding day. At 5.50 a. m., just after sunrise, we entered a region several miles in extent where the marriage flight of Atta versicolor was in full swing. The ants were aggregated in numerous sharply defined swarms, each of which was egg-shaped or elliptical, about six to ten feet long and three to four feet broad, stationary some twenty to thirty feet above and with its long axis perpendicular to the surface of the earth. In some places the swarms were only about forty or fifty feet apart but more frequently the distance between them was fully a hundred feet or as many yards. As far as the eye could see over the desert similar swarms could be discerned. Within each swarm the large dark brown males and females were darting about in vertiginous, zigzag flight. Closer examination showed that each swarm was constantly receiving single males and females flying straight to it from a distance, but it did not grow in size because pairs of ants in copula were constantly raining down to the ground from its lower extremity, so that under each swarm there was a dense layer, often a yard or more in diameter, of writhing and struggling ants. One of the swarms happened to be poised above a puddle of water so that the surface of the latter became black with the fallen pairs. We rode for fully half an hour through these swarms, which must have comprised hundreds of thousands of ants. The activity of the insects was truly surprising, for the workers of versicolor are sedate and slow-moving like all other Attii. The whole phenomenon was rendered remarkably clear and striking 
by the large size and dark color of the ants and their wings, the stillness and purity of the air and the unobstructed view over the level desert. Unfortunately our haste to reach Phoenix before night and the prospect of a very muddy road ahead, made it impossible to stop and observe the conclusion of the flight and the subsequent behavior of the versicolor queens. On previous visits to Arizona I had found the species in the neighborhood of Benson, Tucson and Yucca. The past summer I took it also near Oracle in the Santa Catalina Mountains, near Casa Grande and a few miles from Texas Pass on the western slopes of the Dragoon Mountains. In all these localities the colonies are sporadic and by no means abundant so that it is difficult to account for the vast number of males and females engaged in the flight described above, unless we assume that they represented the entire annual sexual output of a large number of colonies distributed over a very extensive territory.

\section{THE PLEOMETROSIS OF MYRMECOCYSTUS.}

By William Morton Wheeler.

It has long been known that the colonies of some species of ants never possess more than a single fertile queen, whereas in other species several such queens are normally present. Wasmann has recently named the former condition "haplometrosis," the latter "pleometrosis." Among North American ants the species of Camponotus, Polyergus, Pogonomyrmex, Aphœnogaster and Lasius are normally haplometrotic, whereas the species of Formica, Tapinoma, Crematogaster, Pheidole, Monomorium and Myrmica are pleometrotic. This condition undoubtedly arises in most colonies secondarily from a primitive haplometrosis through the deälation and adoption of one or more daughter queens. Large colonies of Formica obscuriventris, e. g., often contain a number of daughter queens in various stages of deälation. The number of queens thus accumulated in some colonies is considerable. I have counted more than thirty in a single medium-sized colony of the typical $F$. fusca, and a single mound of $F$. exsectoides may contain nearly

\footnotetext{
1These terms are equivalent to "monogyny" and "polygyny" employed by students of the social wasps, though somewhat more expressive as they call attention to the maternal or nursing activities.
} 

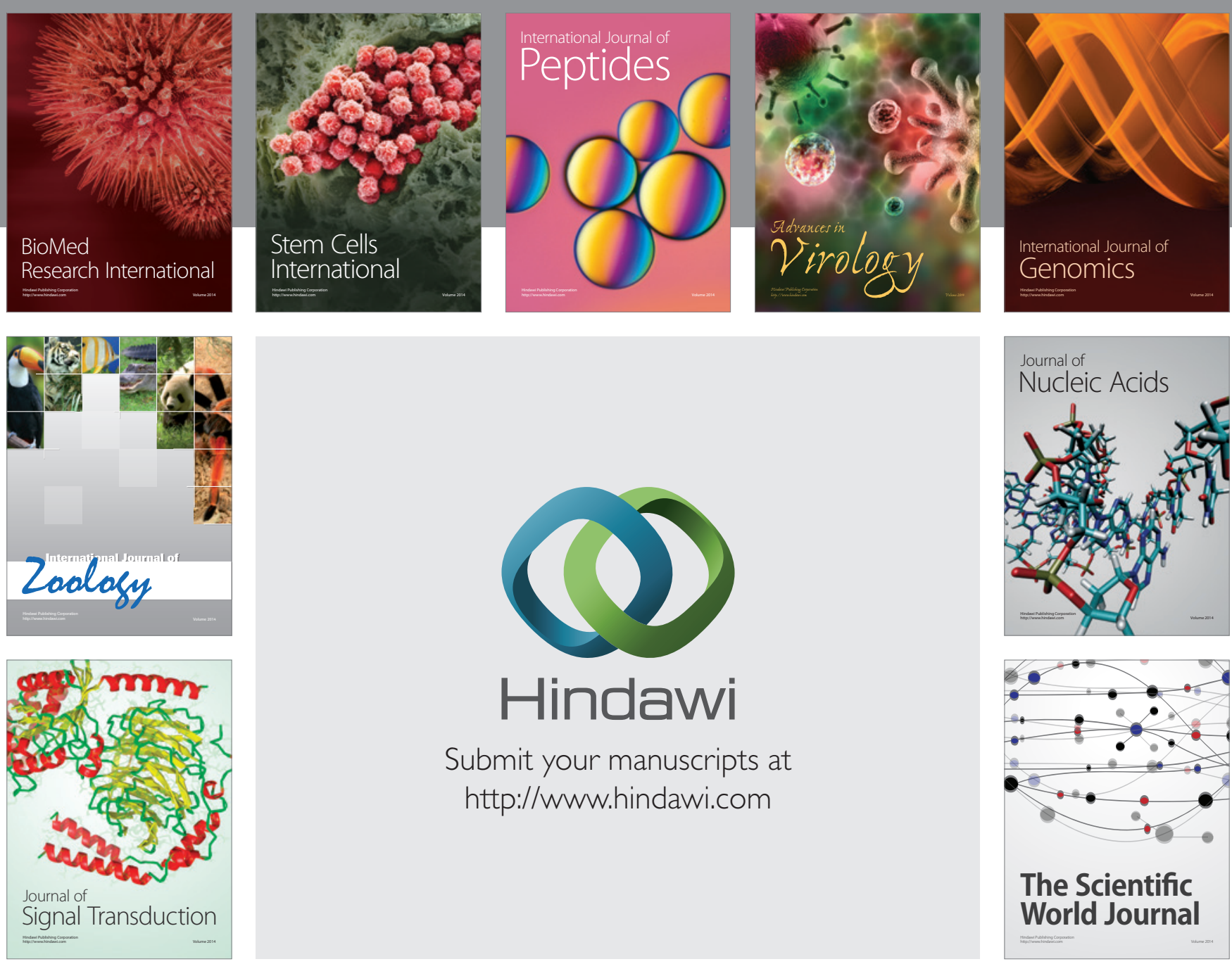

Submit your manuscripts at

http://www.hindawi.com
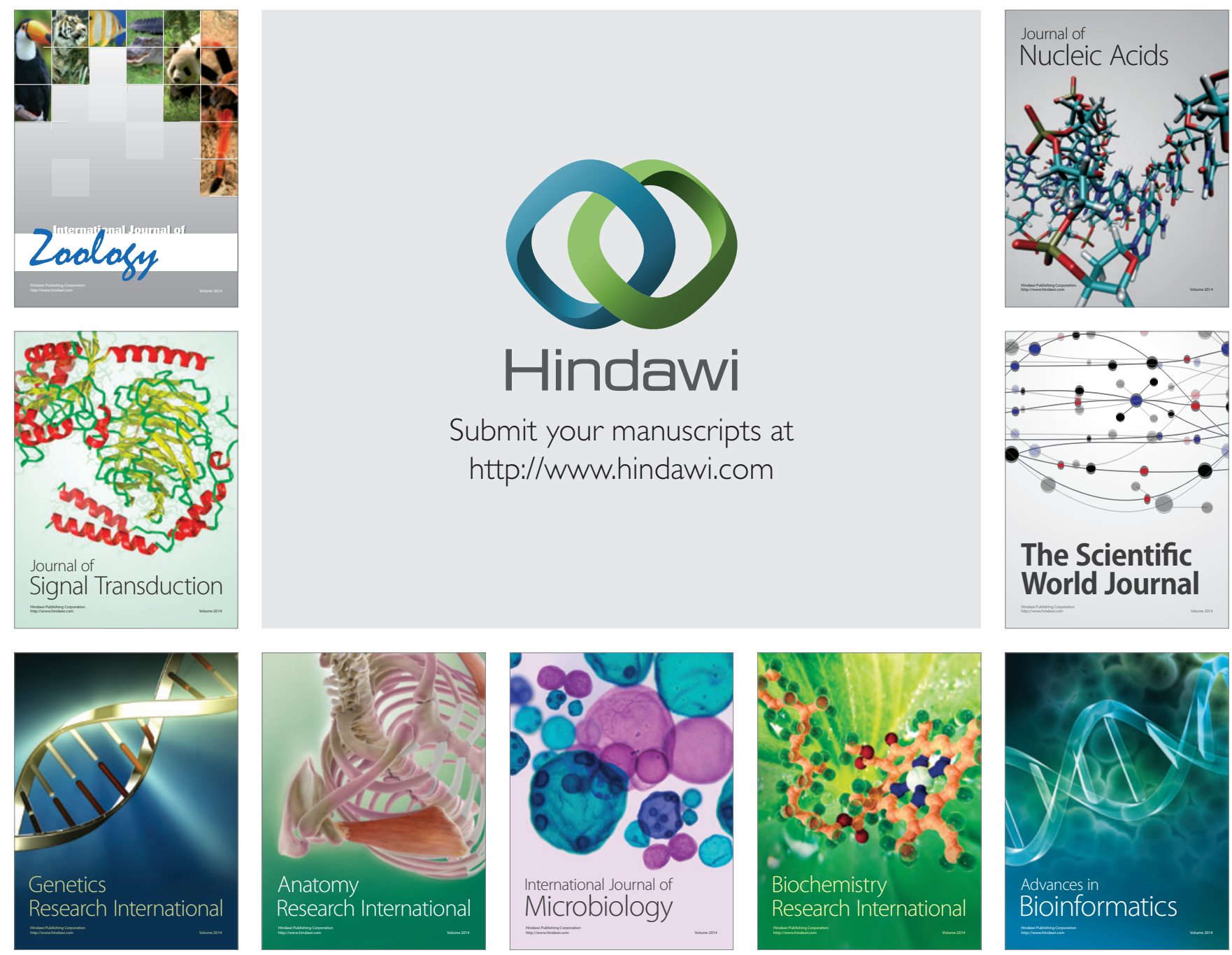

The Scientific World Journal
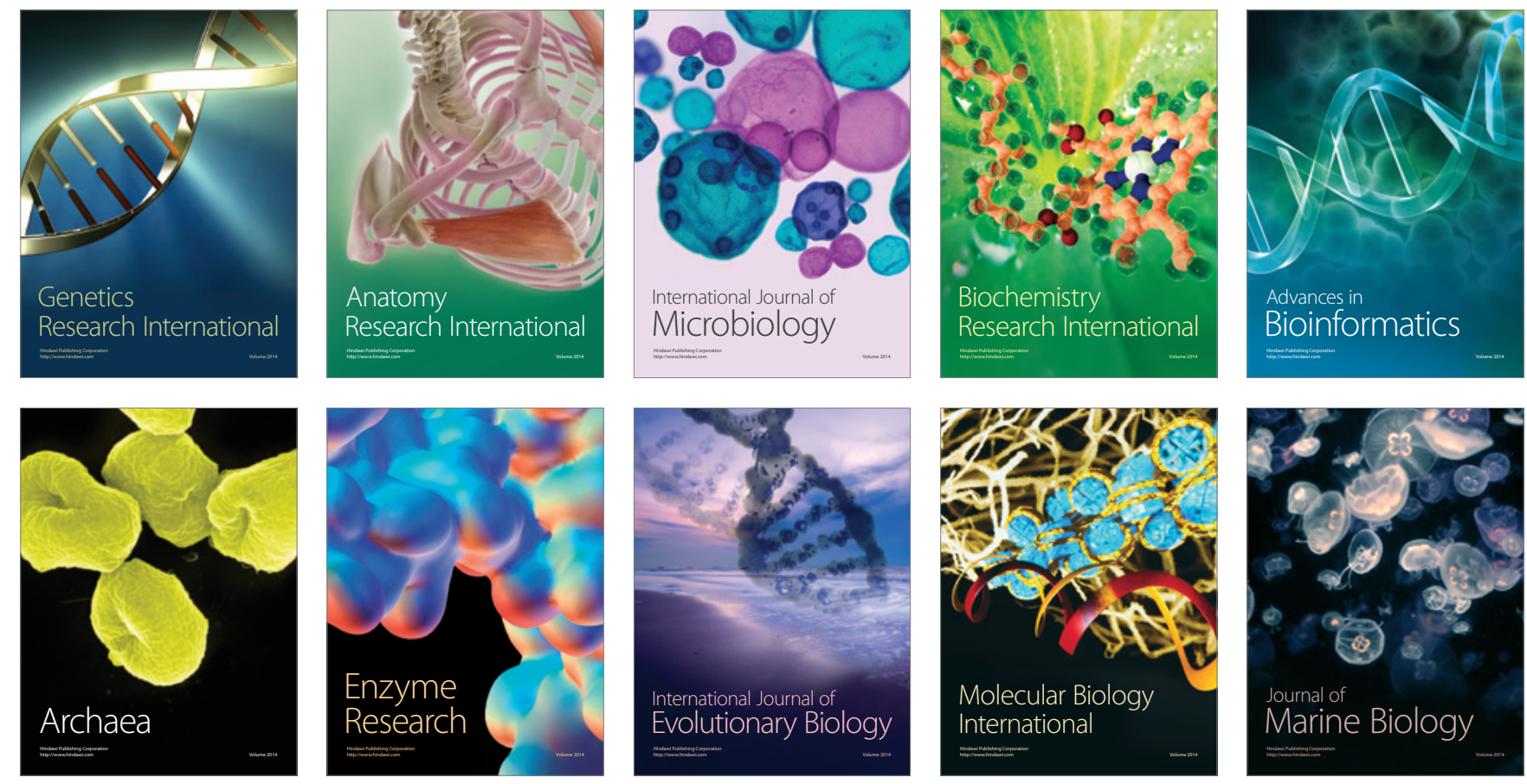